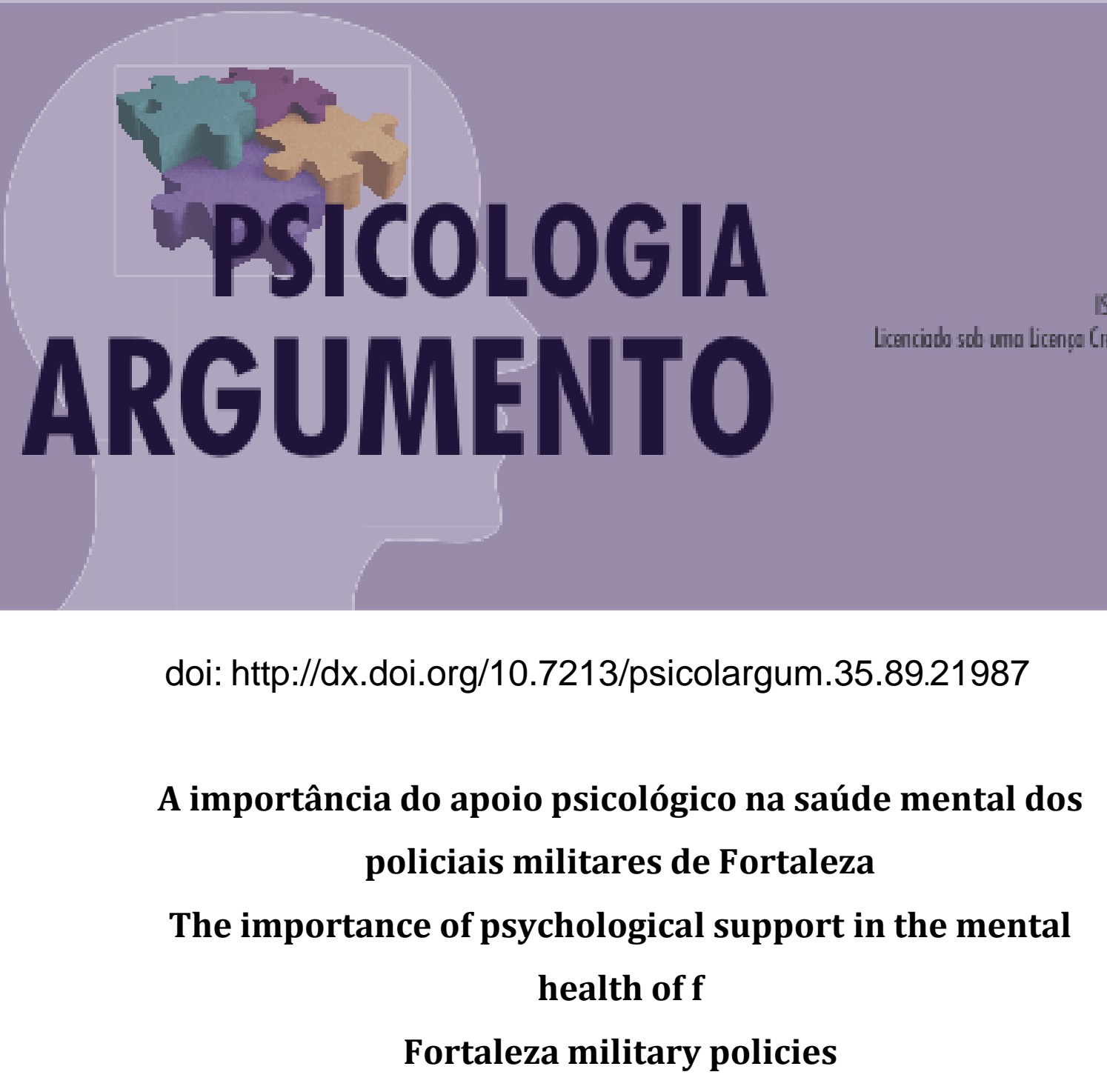

doi: http://dx.doi.org/10.7213/psicolargum.35.89.21987

\title{
A importância do apoio psicológico na saúde mental dos policiais militares de Fortaleza health of $f$
}

Louise Maia Barbosa ${ }^{[a]}$ Catarina Nívea Bezerra Menezes ${ }^{[b]}$

[a] Psicóloga pela Universidade de Fortaleza (UNIFOR)- louisemaiabarbosa@hotmail.com [b] Psicóloga doutora e mestre pela Universidade de São Paulo (USP)- catarinanivea@unifor.br

\section{Resumo}

0 presente trabalho de conclusão de curso teve o intuito de investigar a importância do apoio psicológico na saúde mental dos militares de Fortaleza, bem como se a sua relação com o trabalho gera patologias físicas e/ou psicológicas. Foi dividido em Introdução, metodologia, resultados e discussão e conclusão. Foi realizada uma pesquisa de campo, de caráter exploratório, utilizando a abordagem qualitativa. Para a realização optou-se por trabalhar com entrevistas de aprofundamento, com 5 perguntas norteadoras, e análise de conteúdo. Os participantes foram identificados por patentes sendo estas: Coronel, Capitão, Cabo 1, Cabo 2, Soldado. 0 trabalho demonstrou que a ausência de apoio psicológico, junto ao estresse cotidiano gera muitos prejuízos aos policiais. Concluiu-se que essa questão é multifatorial, mas passível de mudança por meio de estratégias de intervenção baseadas no atendimento psicológico nas regionais, a priori, e futuramente em cada quartel.

Palavras-chave: saúde mental, psicologia, polícia militar, qualidade de vida. 


\section{Abstract}

The present study was aimed at investigating the importance of psychological support in the mental health of the military in Fortaleza, as well as whether their relationship with work generates physical and / or psychological pathologies. An exploratory field research was carried out using the qualitative approach. For the accomplishment we opted to work with deepening interviews, with 5 guiding questions, and content analysis. Participants were identified by patents: Colonel, Captain, Corporal 1, Corporal 2, Soldier. The study showed that the absence of psychological support, coupled with daily stress, causes many losses to the police. It was concluded that this question is multifactorial, but changeable through intervention strategies based on psychological care in the regional, a priori, and future in each barracks.

Keywords: mental health, psychology, military police, quality of life.

\section{Resumen}

El presente trabajo de conclusión de curso tuvo el propósito de investigar la importancia del apoyo psicológico en la salud mental de los militares de Fortaleza, así como si su relación con el trabajo genera patologías físicas y / o psicológicas. Se dividió en Introducción, metodología, resultados y discusión y conclusión. Se realizó una investigación de campo, de carácter exploratorio, utilizando el abordaje cualitativo. Para la realización se optó por trabajar con entrevistas de profundización, con 5 preguntas orientadoras, y análisis de contenido. Los participantes fueron identificados por patentes siendo estas: Coronel, Capitán, Cabo 1, Cabo 2, Soldado. El trabajo demostró que la ausencia de apoyo psicológico, junto al estrés cotidiano genera muchos perjuicios a los policías. Se concluyó que esta cuestión es multifactorial, pero pasible de cambio por medio de estrategias de intervención basadas en la atención psicológica en las regionales, a priori, y en el futuro en cada cuartel.

Palabras clave: salud mental, psicología, polícia militar, calidad de vida.

\section{Introdução}

0 presente trabalho teve por objetivo discutir a importância do apoio psicológico na saúde mental dos policiais militares de Fortaleza. Observou-se que na cidade de Fortaleza, esse contingente carece de cuidados, sobretudo, psicológicos. A hipótese geradora da pesquisa foi de que a inexistência de apoio psicológico nos quartéis, junto a rotina do policial e a pressão do trabalho gera consequências negativas para a sua saúde mental. Para isso destacou-se a história da polícia no País, a concepção de trabalho na atualidade e a forma como a psicologia atua nesse campo. 
A primeira guarda que surgiu no Brasil com características militares foi em 1801, com a ascensão de Dom João III ao reinado. Esta surgiu com a função de estabelecer a administração, promover a justiça e organizar o serviço de ordem pública no Brasil. Contudo, essa organização governamental passou por diversas mudanças até assumir a configuração atual. Atualmente, existem algumas diferenças entre as instâncias militares. As federais (aeronáutica, exército e marinha), as estaduais (polícia militar e bombeiros) que são subordinadas à federal e servem de apoio para as mesmas, e por fim a instância municipal (guarda municipal) (Governo de São Paulo, 2014).

A organização militar no Brasil tem passado por uma desvalorização gradual da individualidade de cada indivíduo que ingressa nessa carreira. Uma vez que esses indivíduos sentem-se desvalorizados e iguais a todos os outros, seu trabalho passa a ser mecanizado e o sentimento de autorrealização acaba. A rotina e a pressão, junto a essa desvalorização podem gerar consequências negativas para a saúde mental dessas pessoas (Dejours, 1999).

O trabalho funciona na dinâmica da autorrealização, onde a identidade constitui a base da saúde mental. Não há crise psicopatológica que não tenha em seu núcleo uma crise de identidade. Essa situação gera muitas psicopatologias, porque ao não contar com os benefícios do reconhecimento do seu trabalho o sujeito se confronta com seu sofrimento de forma direta, sendo um sofrimento que entra dentro de um círculo vicioso desestruturante, capaz de causar doenças mentais. (Dejours, 1999)

Para a Organização Mundial de Saúde (OMS, 1948), "saúde é definida por um estado de completo bem-estar físico, mental e social e não somente ausência de afeções e enfermidades". Mas na prática é difícil determinar quando uma pessoa está saudável ou não. (Campos \& Rodrigues, 2014, p.232)

Independente de qualquer conceito a Declaração Universal dos Direitos Humanos (DUDH) garante ser de direito de qualquer pessoa ter saúde e condições suficientes que lhe assegurem viver em sociedade. Diz o Artigo $25^{\circ}$ 
(1).Toda pessoa tem direito a um nível de vida suficiente para lhe assegurar e à sua família a saúde e o bem-estar, principalmente quanto à alimentação, ao vestuário, ao alojamento, à assistência médica e ainda quanto aos serviços sociais necessários, e tem direito à segurança no desemprego, na doença, na invalidez, na viuvez, na velhice ou noutros casos de perda de meios de subsistência por circunstâncias independentes da sua vontade. (Constituição, 1988)

Percebe-se que faz parte das garantias o direito a saúde integral, o que quer dizer que a saúde mental do sujeito também está inserida nos direitos do ser humano. Por isso, a psicologia também está dentro dessa discussão de forma transdisciplinar, perpassando todo o processo de saúde e doença, e investindo na atuação em diversos ambientes. Esta atua, sobretudo, entendendo o sujeito do ponto de vista biopsicossocial, que significa olhar para o homem de forma holística, e não apenas para partes. Portanto, atua para garantir que sua completude esteja saudável. (de Oliveira \& dos Santos, 2010)

Para se chegar aos direitos à saúde do trabalhador, o conceito de trabalho passou por muitas transformações. Ele surgiu na Modernidade a partir da relação de três fenômenos: o Capitalismo, o Iluminismo e a noção de Estado-Nação. Tal conceito, ao longo dos anos, sofreu muitas transformações, dentre elas, nos contextos social, político e econômico. $\mathrm{Na}$ categoria homogênea, o trabalho se consolidou junto com a noção de riqueza, de produção e com a ideia de sistema econômico por volta do século XVIII, isto é, a noção (antropológica) de trabalho que se tem atualmente é fruto da Modernidade, antes disso não havia existido em outras culturas como se conhece atualmente. (Bernal, 2010)

Desse modo, observa-se de acordo com as épocas que o trabalho passou de uma desvalorização, como ocorria na Antiguidade, à uma paulatina valorização do mesmo ao longo da história. Na Grécia, por exemplo, esta atividade era desempenhada por indivíduos considerados inferiores. Foi ainda no período da Revolução Industrial que o conceito começou a ser compreendido como uma força capaz de criar valor, 
tornando-se um pilar da riqueza das nações. Atualmente, é visto como algo que constitui o humano (Bernal, 2010).

A aparição do indivíduo na cena pública favoreceu o surgimento desse conceito, o conceito de trabalho. Este logo tornou complexa a subjetividade individual, pois configurou-se como a relação social nuclear, isto é, a relação do sujeito com a sociedade passou a ser realizada por meio do trabalho. Seu nascimento data do século XVIII e sua grande evolução encontra-se no século seguinte, quando trabalho ganhou o significado idealista de autorrealização pessoal, expressão de criatividade e de autonomia do Eu. Sobretudo, na época atual, o trabalho é considerado como parte fundamental da subjetividade humana, havendo uma supervalorização do mesmo como jamais vista antes (Bernal, 2010).

Por esse motivo o próprio trabalhador exige muito de si mesmo e por diversas vezes se frustra não atingindo seus objetivos, não observando criticamente o sistema adoecedor. Vê-se assim que a preservação da subjetividade do sujeito e da saúde mental dele não são proporcionais à supervalorização do trabalho (Andrade \& Souza, 2010).

No âmbito militar não é diferente, pois o trabalho perpassa a subjetividade de cada policial. No Brasil, a polícia tem sua organização e divisões de patentes, por isso o presente trabalho não visa se deter a tais divisões, mas ao campo da psicologia na saúde mental que perpassa todos eles (Couto, Vandenberghe \& Brito, 2012).

A motivação inicial partiu da observação de que há muita demanda de policiais que precisam do serviço de psicologia, para poucos psicólogos atuando nessa área. A motivação pessoal decorreu do fato de que vê-se a necessidade de que a psicologia alcance todos os campos profissionais, sobretudo àqueles mais precários, onde há extrema necessidade, como o militar (Minayo, Assis \& de Oliveira, 2011).

0 trabalho possui significativa importância para o futuro profissional dos estudantes de psicologia em geral, sobretudo para aquele que se interessa em conhecer novas áreas de atuação dessa profissão. Através da problemática podemos compreender como se dá a relação do policial com o trabalho, a fim de que se compreenda todos os aspectos 
patológicos envolvidos no seu exercício laboral, bem como as propostas de intervenção possíveis para garantir seu bem-estar.

\section{Metodologia}

O trabalho classificou-se como um estudo exploratório, com a finalidade de proporcionar mais informações sobre o assunto que investigado, visando alcançar os objetivos, formulação de hipótese e análise do discurso. Para isso foi utilizada a abordagem qualitativa, sendo embasada na revisão bibliográfica e na pesquisa de campo que ajudou na compreensão do tema. Para a pesquisa bibliográfica foram utilizados como embasamento artigos do SCIELO (Scientific Electronic Libery, Online) e livros e-book do Google Acadêmico.

Para a construção desse estudo, optou-se por utilizar 12 artigos, publicados de 2000 a 2015, que atendiam aos requisitos necessários para serem utilizados, sendo selecionado um total de 12 artigos relacionados a saúde física e mental dos policiais militares e os impactos do trabalho na qualidade de vida deles. Estes foram escolhidos a partir das palavras chaves "saúde mental", "psicologia" e "polícia militar". Ao pesquisar as palavras chaves no google acadêmico foi encontrado aproximadamente 1.700 resultados.

A pesquisa foi realizada após aprovação do Comitê de Ética (COÉTICA) em um quartel da polícia militar do Ceará, em Fortaleza, o qual terá identificação preservada. Esse quartel insere-se na Administração Pública Estadual como órgão subordinado ao Governador do Estado e vinculado, operacionalmente, à Secretaria da Segurança Pública e Defesa Social.

Para a da coleta de dados foi primeiramente realizado um pedido na Controladoria Geral para a concessão de um documento permitindo a realização de entrevistas com cinco policiais. Depois, o telefone da pesquisadora foi divulgado em cartazes afixados nos flanelógrafos, a fim de que o policial que desejasse participar entrasse em contato, gerando assim participação voluntária. 
Participaram aqueles que consideraram o estudo relevante para futuros benefícios na sua profissão. A coleta de dados foi realizada por meio de entrevistas semiabertas com perguntas norteadoras para policiais militares que trabalham em um quartel de Fortaleza, partindo da temática central do trabalho, no período dos meses de Fevereiro a Junho de 2017.

A entrevista foi gravada com a permissão dos entrevistados, após a assinatura do Termo de Consentimento Livre e Esclarecido e posteriormente foi transcrita para melhor análise e compreensão dos dados recolhidos. Na transcrição os nomes foram omitidos sendo nomeados por patentes, a fim de organizar as falas dos participantes. Serão identificados por Coronel, Capitão, Cabo 1, Cabo 2 e Soldado.

O material obtido por meio das gravações foi utilizado somente nesse trabalho e, após transcrito, foi eliminado, assim como todo e qualquer tipo de mídia, restando nada que viesse comprometer o anonimato do participante. Puderam participar da pesquisa pessoas do sexo masculino, com idade entre 25 a 56 anos, de nacionalidade brasileira, atuantes em Fortaleza. Não puderam participar reservistas, estrangeiros, atuantes fora de Fortaleza.

As entrevistas gravadas com autorização dos participantes foram transcritas e analisadas individualmente, gerando um levantamento das principais alterações físicas e psicológicas, bem como das consequências delas na saúde mental desses militares.

Foi utilizada para a análise qualitativa dos dados a Análise de Conteúdo, conforme Bardin (1977), esta é uma técnica utilizada para análise de comunicações, sendo objetivada, por procedimentos sistemáticos e diretos na realização da descrição do conteúdo das mensagens, indicadores que se permitam chegar a uma conclusão de informações e conhecimentos referentes à produção e recepção destas mensagens.

Os fatores analisados nos discursos foram o estresse ligado ao trabalho, bem como todos os fatores que influenciam para que esse trabalho se torne menos prazeroso. Também foi analisado a relação deles com a 
doença que afeta a sua saúde mental, assim como a relação da prática com a teoria sobre saúde e qualidade de vida.

No presente trabalho foram respeitados os aspectos éticos fundamentais, respeitando a Resolução 466/12 do Conselho Nacional de Saúde e com o devido consentimento livre e esclarecido do policial, não havendo discriminação na seleção dos indivíduos entrevistados. Ademais não foram realizados julgamentos que pudessem prejudicar os entrevistados e a sua confidencialidade, mantendo a sua privacidade.

0 procedimento utilizado (Entrevista) podia trazer riscos como constrangimentos, tristeza, angustia, podendo ser amenizados pela pausa da entrevista ou o por seu encerramento. Contudo, a forma compreensiva de o pesquisador abordar as perguntas também amenizou os riscos da pesquisa. Caso acontecesse alguma exposição desconfortável o mesmo seria acolhido e encaminhado a um setor de Psicologia onde poderia usufruir do apoio psicológico necessário. Foi esclarecido ao entrevistando que a entrevista poderia ser interrompida no momento que desejasse.

Os benefícios esperados com a pesquisa foram no sentido de compreender a saúde mental do policial militar dentro de um contexto de pressão, demonstrando a importância do apoio psicológico para eles. Este teve como finalidade maior entender de que maneira podia-se ajudar os policiais no enfrentamento aos problemas, aumentando a literatura sobre este assunto e dando suporte em algumas questões tanto para os policiais como para os profissionais de saúde.

Este trabalho teve como objetivo avaliar a relação do policial com o seu exercício laboral, observando os aspectos relativos à saúde mental deles, bem como avaliar de que maneira a ausência de apoio psicológico interfere na qualidade de vida desse contingente. Dessa forma, como benefício à comunidade científica e aos envolvidos na pesquisa, intentou produzir conhecimento válidos de como a Psicologia pode intervir auxiliando na compreensão e na utilização de técnicas que visam proporcionar uma melhoria na qualidade de vida dos policiais militares. 


\section{Resultados e discussão}

\section{Caracterização geral dos participantes}

Participaram do trabalho 5 policiais do sexo masculino, com média de idade de 38 anos, média de serviço de 17 anos e patentes variadas desde soldado até coronel.

O soldado tem 25 anos, ingressou por meio de concurso público e relata que sua motivação foi o fato de gostar muito de ajudar as pessoas e orientá-las. 0 cabo 1 prestou concurso público em 2009, tem 32 anos e considera que seu trabalho tem grande importância para sua família. 0 cabo 2 tem 26 anos de idade e também entrou em 2009, por meio de concurso público. Estudou a maior parte da vida em escola militar, recebendo muita influência desse contexto. Passou aos 17 anos e teve que esperar a maioridade para ingressar no sistema militar.

0 capitão tem 33 anos de serviço, e 56 anos de idade. Foi admitido após um curso de sargentos, é pai, marido e filho. Considera que sua família sofreu as consequências da sua opção pelo militarismo, porém não se arrepende, porque aprendeu muito com todas as experiências. 0 coronel tem 54 anos, fez provas intelectuais, médicas, físicas e depois psicológicas no ano de 1984, a fim de ingressar na polícia militar. Relatou que seu objetivo era um emprego que dessa estabilidade para ele e sua família.

Participaram do trabalho 5 policiais que reconhecem ter uma importância muito grande para a sociedade, família e para as autoridades, porém todos relataram não terem o reconhecimento esperado. Desse modo, foi desenvolvida a pesquisa, sobretudo, por meio da colaboração dos mesmos em suas respostas.

\section{Caracterização específica do policial e do campo de atuação}

Os participantes são profissionais que foram atraídos pela estabilidade financeira, bem como pelo desejo de fazer justiça contra o crime. Porém, frustraram-se com o pouco reconhecimento por parte da sociedade e das autoridades.

Algumas vezes somos reconhecidos e na maioria das vezes não. Na verdade eles (autoridades) querem que sejamos submissos sem 
questionar, senão você fica abandonado no problema, não é promovido... é um jogo, você tem que saber jogar: se você for do sistema você ganha, se não for você fica ali calejado (Coronel da polícia militar, 2017)

São profissionais que trabalham em situações constantes de risco de morte e pressão psicológica, bem como possuem alta carga horária, porque o serviço funciona em regime de escala. A partir dos discursos, percebeu-se que a depender da cultura dos entrevistados os fatores como, resiliência e satisfação podem variar, bem como o modo de compreender e vivenciar o sistema militar também (Couto \& Brito, 2012).

A classe dos policiais entrevistados são um contingente refém da violência e de uma rotina de exposição ao crime, por isso propõe uma formação exigente com alto grau de impactos físicos e doenças crônicas no corpo. Na fala do Capitão ele diz que nele ficaram várias sequelas: "Contrai 3 hérnias de disco na coluna cervical, desgaste profundo em toda a extensão da minha coluna vertebral, repleta de esporões, isso tudo testificado através de ressonância magnética e acompanhado por um especialista e cirurgião". E o Cabo 2 acrescenta que o próprio serviço requer um bom preparo físico, porque segundo ele, por mais tranquilo que pareça, eles pesam no mínimo $10 \mathrm{~kg}$ a mais quando estão equipados para trabalhar. As consequências são: problemas nos joelhos, nas costas e, as vezes, na circulação também.

0 contexto desse cenário é a cidade de Fortaleza, caracterizada no cenário nacional como a $2^{\underline{a}}$ cidade mais violenta do Brasil, tendo altos índices de homicídios, roubos e agressão. A regional VI tem os índices mais críticos e as maiores necessidades sociais (UECE, 2009)

Com isso, vive-se com constante sensação de medo devido ao contexto de violência. 0 agravante é a impunidade e a desigualdade de direitos, entre o infrator e o policial. Por isso, são tantas queixas da parte dos policiais militares que tentam combater o crime, mas muitas vezes não conseguem e ressaltam constantemente a importância de penalidades mais rígidas para os criminosos (de Oliveira, 2015).

Essa impunidade incentiva os caras, hoje é triplicado o estresse psicológico e físico que você tem. Você tem que ir pro serviço e 
procurar sair vivo! Numa situação de tiroteio você tem que pensar duas vezes se vai atirar, porque atrás do bandido pode ter um terceiro sem relação com o crime e se você atirar pode atingir essa pessoa. 0 bandido não, ele larga bala lá... se o policial morreu tudo bem, o bandido vai preso por um tempo, passa lá dois anos. Depois ele sai, ai vai ressocializar o preso... e o policial que morreu fica esquecido. Então sempre digo saia vivo! (Coronel da polícia militar, 2017).

Isso tudo colabora para o desenvolvimento de uma polícia adoecida psiquicamente também. São inúmeros problemas advindos do trabalho desequilibrado: depressão, transtorno do pânico, transtorno bipolar, esquizofrenia, manias de doença(hipocondria) e tentativas de suicídio em grande escala (Minayo, Assis \& Oliveira, 2011).

Para o Soldado diagnosticado com transtorno bipolar, ao ingressar, foi a primeira vez que ele lidou com situações difíceis como tiroteio, brigas, homicídios. Ele relata "comecei a dormir mal e isso me impactou psicologicamente e fisicamente, não tive nenhum apoio nesse momento, só me indicaram o CAPS". O capitão fala que existem policiais diuturnamente na rua que sofrem de algum transtorno mental, como depressão, síndrome do pânico, estresse intenso, claustrofobia, esquizofrenia, e outros. Eles precisam de acompanhamento. A maioria dos policiais não estão preparados para o enfrentamento de situações de estresse intenso, com isso não têm equilíbrio emocional para superar as situações adversas.

Durante o período de formação eles treinam bastante, a fim de manter o nível de excelência no trabalho. Eles ressaltam que esse treinamento é importante e que eles se sentem capacitados para o serviço, mas com o desenvolver do trabalho sentem os impactos no corpo.

\section{Homem na atualidade}

Visto isso, sabe-se que em parte o grau de exigência citado acompanha uma mudança na visão do homem na atualidade, bem como sua relação com o trabalho. Para Tadeu (2009) uma das características mais marcantes da modernidade é a conjunção entre homem e máquina. Todos 
os entrevistados relataram sentirem-se esgotados apesar de o sistema sistema proporcionar-lhes formação de excelência no regime militar e os tornarem cidadãos e líderes melhores, ensinando bons valores éticos e morais.

Para o coronel "a nossa formação nos dá muitos valores, nos ensina a ser éticos, a respeitar os superiores, a respeitar os seres humanos, a disciplina e na nossa sociedade não se existe sem isso". Apesar disso, o autor considera que essa transformação através das épocas gera uma confusão entre ciência e política, tecnologia e sociedade e entre natureza e cultura, ao ponto de gerar questões ambíguas para o próprio homem (Tadeu, 2009, p. 10).

Esse homem apesar de ser atraente, dinâmico e divertido é extremamente vulnerável, pois apesar de viver na era da informação não consegue administrar bem os conteúdos aprendidos. Além disso, o homem moderno assume uma marca de indefinição, de inconstância, de versatilidade. Costuma viver com constante estresse, pessimismo, desencanto e, acima de tudo, depressão (Rojas, 1996, p. 61). Sobre isso o Cabo 1 relata "Vejo também a cobrança pessoal como ponto negativo. A gente acaba se cobrando pra ser melhor e sempre mais e mais e isso gera muito impacto, porque chega uma hora que queremos fazer justiça com as próprias mãos, queremos ver as coisas certas".

O processo de mudança no sistema produtivo na pós-modernidade exigiu do trabalhador mais esforço e capacidade de adaptação. Essas mudanças afetam a maneira de ser do trabalhador e contribuem para desemprego, diferença salarial e desvalorização da força de trabalho, porque o foco nos resultados passou a balizar o trabalho, não importando como se chega a eles (Antunes, 2008). Desse modo temos atualmente um sistema de produtividade que visa o lucro em detrimento do bem estar do trabalhador.

Não somos reconhecidos por quem deveria, somos regidos por uma legislação muito retrógrada onde se beneficia apenas o criminoso. Ai gera insegurança. A gente não se sente seguro e livre para trabalhar diante de um sistema, que é muito influenciado por instituições hipócritas, que 
defendem falsos direitos humanos. Até parece que gostam de culpar sempre a polícia, tudo e todos acham mais fácil culpar e punir o policial. Mas ninguém se preocupa com a gente. Um agente só age energicamente quando o que acontece? Depois que tudo falhou! A família, a educação, os serviços sociais, tudo! (Cabo 2 da polícia militar, 2017).

\section{Apoio psicológico na saúde mental dos policiais militares}

O conceito atual de saúde diz respeito a muitos elementos que estão interligados. Estar saudável vai além de não estar doente, mas está atrelado a diversos fatores como: como lazer, trabalho, moradia, educação, entre outros, que devem estar em um equilíbrio para proporcionar a saúde do homem. 0 modelo brasileiro que deve dar suporte à população é inspirado em outros modelos como o da Inglaterra, o de Cuba e o do Canadá, os quais investem sobretudo na promoção da saúde, ao contrário de outros que priorizam a prevenção. A promoção de saúde trata o sujeito antes da sua doença (Contini, 2000).

O Sistema Único de Saúde(SUS) que foi pensado e criado em meados da década de 70 e 80 tem como ideias filosóficas básicas: a universalidade, a integralidade e a equidade. Assim, tem-se que todos deveriam ser atendidos de forma integral, sem restrições e de forma proporcional a sua necessidade. Contudo, devido à má gestão de recursos, falta a assistência que essa população tanto precisa (Paiva \& Teixeira, 2014).

Sendo a saúde essencial para todo ser humano, no campo psicológico ela não pode ser negligenciada aos policiais militares, porque a sua qualidade de vida fica comprometida. Para as pessoas que dependem exclusivamente do SUS a situação torna-se ainda mais difícil, porque se o policial adoecer ele fica na dependência de filas extensas de espera, a fim de conseguir atendimento e medicação que deveria ser de emergência. Além disso, fica afastado do serviço e perde bonificações em dinheiro que ajudam no seu sustento. O sistema portanto precisa passar de uma postura remediadora e para uma preventiva e de promoção da saúde (Couto, Vandenberghe \& Brito, 2012). 
Hoje estou sob tratamento, acompanhado por um psiquiatra particular, a base de medicamentos, ansiolíticos e anti-depressivos (Lexapro e Frontal), caríssimos, em que a polícia militar e o governo do Estado não me oferecem a mínima condição, pelo menos para amenizar esse processo de dor e recuperação. Me faltam condições financeiras para manter o tratamento e buscar ajuda (Capitão da polícia militar, 2017)

Os policiais entrevistados sentem falta de apoio para si e para sua família, porque relatam que o trabalho influencia bastante suas relações familiares, tanto positivamente quanto negativamente. Para eles, o acúmulo de relações interpessoais frágeis gera mais insatisfação e estresse.

E ao contrário do que muitos pensam, o fato de eu ser um policial militar, diretamente, não ajuda em nada em relação a segurança da minha família, já que quando saio para o trabalho deixo ela em casa para cuidar de outras famílias! A questão é que quase nunca estamos em casa e ai é impossível acompanhar meus familiares o tempo todo (Cabo 2 da polícia militar, 2017)

Além disso, a carga de trabalho priva os policiais de aproveitarem momentos de lazer, que é um fator também constitutivo da saúde mental. Para o capitão o que os leva ao adoecimento é não terem folga suficiente para conviver em família, não terem lazer, tampouco tempo para eles mesmos, até para investir em formações universitárias. Ele completa "Muitas vezes, a folga é interrompida com escalas extras para atender a eventos, como shows, futebol, blitz e outras coisas. Muitos vão trabalhar doentes, pois se você for procurar uma unidade hospitalar e obtiver repouso medico, você perde algumas gratificações".

Sobre essa mesma temática o coronel conta que teve sorte ao conseguir cursar outras formações e que as oportunidades não surgirão com facilidade. Mas admite que a profissão tem ganhos por um lado e perdas por outro. Ele lamenta ter perdido muitas coisas devido ao sistema de escalas. Ele usa a expressão "trabalhamos muito". Ele cita um exemplo de sua vivência pessoal 
Por exemplo momentos com a minha filha e até com minha esposa... realmente tem esse aspecto que em muitos momentos eu estava trabalhando e viajando para o interior, estava em um final de ano trabalhando na beira-mar. Muitos momentos eu perdi com a minha filha e hoje tem algumas coisas que ela sente falta. E criança precisa da presença do pai, eu sei disso, mas no futuro ela entenderá que era por questões financeiras, para manter a família (Coronel da polícia militar, 2017).

Outro aspecto relevante é o impacto psicológico que começa nos anos iniciais do exercício laboral, quando a rotina muda drasticamente, colocando um civil equipado contra o crime. Isso envolve armamentos de difícil manuseio, regras e uma violência vista por outro ângulo: o de quem protege. A responsabilidade repentina gera profundas mudanças no psicológico e a pressão passa a fazer parte da rotina desse contingente (Souza \& Minayo, 1995). 0 cabo 2 diz:

Depois de entrar na polícia tudo testa nosso psicológico. De uma simples sensação de portar uma arma, até o ponto de ser alvejado por um disparo de arma de fogo, como aconteceu comigo. Nossa profissão tem risco de morte o tempo todo, a gente presencia todo tipo de crime, corpos humanos destruídos de várias maneiras, uma sensação de ameaça constante, todo tempo, todo tempo (Cabo 2 da polícia militar, 2017).

Assim, considera-se que a mudança repentina, junto a impunidade característica da cultura brasileira, têm influenciado o processo de adoecimento dos policiais militares, o qual independe de patente para acontecer. Esse adoecimento envolve desde desgastes simples de rotina até psicopatologias severas, gerando estresse e sensação de falta de garantia à vida (Ferreira, Bonfim e Augusto, 2011).

0 fator mais citado como gerador de estresse é a falta de reconhecimento, seguido por falta de garantia a vida. E o sentimento mais recorrente entre esse contingente é o medo. Nos últimos anos a violência tem se acentuado, não apenas contra civis, mas também contra militares (Uece, 2009). 
Para o Coronel esse fator é resultado de uma cultura que promove o ódio contra a polícia, mantido por ideologias. Para ele essa ideologia propagada atrapalha seu trabalho, gerando ainda mais insatisfação da classe, porque coloca a população contra o contingente. Apesar disso, na visão deles, a profissão os ensina a persistir em todas as situações gerando resiliência. Isso tem sido citado como um fator positivo que equilibra tantos impactos negativos e os ajuda a manter-se na ativa.

Mas o resultado são pessoas adoecidas cuidando de outras em uma civilização que apresenta-se como uma bomba-relógio. 0 problema piora cada vez mais e os benefícios do regime militar não conseguem competir com as falhas do sistema desigual. Esse sistema é regido por valores da instituição. (Guirado, 1987).

A psicologia entra no contexto militar como parte dele, mas promovendo diálogos e propostas de mudanças. O olhar do psicólogo para qualquer ser humano deve ser pautado na ética e na visão holística do homem. Ele é um ser biopsicossocial, que não necessita apenas de uma boa alimentação, mas também de cuidados com o psicológico. Não há uma visão dual corpo-mente, mas um encontro de ambos, sendo afetados pelo ambiente (Alves, 2011)

É um homem dotado de múltiplas inteligências, capaz de apreender e aprender regras e coloca-las em prática. Assim como possui essas semelhanças, também distingue-se quanto ao modo como o organismo reage às ações do ambiente, assim sendo passível de reações não condizentes com as regras (Gardner, 1995, p 54).

A importância da visão psicológica é de que é possível entender o homem dentro da cultura brasileira, de acordo com a região em que se encontra, na cidade o qual reside. Por isso, avalia-se as suas patologias de forma multifatorial, porém não obrigatoriamente concordante com suas ações. Nessa discussão é essencial o olhar crítico e ao mesmo tempo compreensivo, demonstrando sensibilidade, equilíbrio e respeito, o qual o psicólogo estuda muitos anos para desenvolver (Bock, 2009, p. 13).

Assim, a ajuda de um profissional de psicologia pode promover a saúde por meio desse olhar e de técnicas assertivas relacionadas ao estresse 
nessa área específica. 0 psicólogo também pode gerar um ambiente de maior compreensão interpessoal e enfrentamento dos problemas, bem como reunir as características necessárias para ajudar esse contingente de forma imediata (Terapia breve focal) ou a longo prazo (psicoterapia individual ou de grupo) (Contini, 2000, p. 46).

\section{Conclusão}

Assim, faz-se necessário uma proposta interventiva que amenize a problemática e abra espaço para mais profissionais se envolverem nas questões relacionadas à psicopatologias e ao campo militar. Devido à violência em Fortaleza, torna-se essencial atender cada policial em crise ou em fase de estresse latente.

0 serviço de psicologia nos quarteis pode promover 0 autoconhecimento da equipe por meio de palestras sobre enfrentamento e os limites do corpo (físico e mental). Além disso, debates interdisciplinares sobre a saúde é uma estratégia de promoção e não apenas prevenção dos problemas encontrados, promovendo junto a psiquiatria as informações básicas sobre qualidade de vida no contexto militar e no âmbito da saúde mental.

Existe também uma grande necessidade de o psicólogo atuar em parceria com o comando militar, sobretudo em relação ao preparo psicológico no ingresso da profissão, porte de arma e situações de combate, as quais são as principais demandas relatadas nas entrevistas. Esses assuntos e outros poderiam ser trabalhados em plantões psicológicos, os quais contariam com 24 horas de disposição de uma equipe de psicólogos divididos, inicialmente, entre as 6 regionais de Fortaleza, e futuramente, em cada quartel.

É necessário mudar essa situação e começar a direcionar o olhar para além dos resultados que um policial pode dar, entendendo-o em seu contexto, respeitando suas necessidades como as de qualquer ser humano. Independente da mudança do contexto, as necessidades desses policiais são de urgência. Vê-se, portanto, que o apoio psicológico é essencial. Nas palavras do Cabo 2 "Eu acho que aquele que se aposenta na polícia sem 
nenhuma alteração psicológica, não foi polícia de verdade. Pra falar a verdade eu nunca vi apoio psicológico nos quarteis."

Ademais, durante esse trabalho algumas dificuldades foram superadas, como a concessão da autorização para realizar as entrevistas, o deslocamento pela cidade e a participação dos voluntários. Apesar dos percalços, a análise dos discursos foi concluída, gerando conclusões de grande importância pessoal e para a comunidade científica. Para a sociedade tem grande relevância, visto que é um tema atual e de constantes debates acerca das propostas interventivas para amenizar o problema.

Confirmando a hipótese inicial e promovendo discussão acerca de possíveis intervenções para o contingente militar de Fortaleza, o presente trabalho não objetivou esgotar o tema da psicologia relacionada à polícia militar, mas intentou proporcionar informações reais com a finalidade de gerar mais estudos na área, bem como o diálogo sobre ela.

Por fim, o presente trabalho também teve por finalidade gerar mudança no contexto da psicologia militar em Fortaleza e também, por consequência, na região Nordeste. É necessário que concursos públicos para psicólogos sejam abertos e que haja uma valorização e reconhecimento do potencial desse trabalho na vida dos policias e para a sociedade.

\section{Referência}

Alves, R. F. (2011). Psicologia da saúde: teoria, intervenção e pesquisa. EDUEPB. Retirado de http://static.scielo.org/scielobooks/z7ytj/pdf/alves9788578791926.pdf Acesso em 05 de abril de 2017.

Andrade, E. R. D., \& Souza, E. R. D. (2010). Autoestima como expressão de saúde mental e dispositivo de mudanças na cultura organizacional da polícia. Psicologia Clínica, 22(2), 179-195.

Antunes, R. L. (2008). Adeus ao trabalho?: ensaio sobre as metamorfoses e a centralidade do mundo do trabalho. Rio de Janeiro: Cortez. 
Bernal, A. O. (2010). Psicologia do trabalho em um mundo globalizado: como enfrentar o assédio psicológico e o estresse no trabalho. Porto Alegre: Artmed, 29-32.

Bardin, L. (1988). Análise de conteúdo. Lisboa/Portugal: Edições 70, 2008. BRASIL. Ministério da Educação. Livro didático, 19-24.

Bock, A. M. B., Furtado, O., \& Teixeira, M. D. L. T. (2009). Psicologias: uma introdução ao estudo de psicologia. São Paulo: Saraiva, 13.

Campos, M. O., \& Rodrigues Neto, J. F. (2014). Qualidade de vida: um instrumento para promoção de saúde. Revista Baiana de saúde pública, 32(2), 232.

Carlos, G. A. (2008). Métodos e técnicas de pesquisa social. São Paulo: Atlas.Constituição brasileira. Retirado de http://www.planalto.gov.br/ccivil 03/Constituicao/Constituicao. htm. acesso em 22 de outubro de 2016.

Contini, M. D. L. J. (2000). Discutindo o conceito de promoção de saúde no trabalho do psicólogo que atua na educação. Psicologia: Ciência e Profissão,20(2), 46-59. Retirado de http://www.scielo.br/scielo.php?script=sci arttext\&pid=S141498932000000200008 Acesso em 26 de março de 2017.

Couto, G., Vandenberghe, L., \& Brito, E. D. A. G. (2012). Interações interpessoais e estresse entre policiais militares: um estudo correlacional. Arquivos Brasileiros de Psicologia, 64(2), 47-63.

Dejours, C. (1999). Banalizacao Da Injustica Social, a. FGV Editora, p.35. da Silva Ferreira, D. K., Bonfim, C., \& da Silva Augusto, L. G. (2011). Fatores associados ao estilo de vida de policiais militares. Ciência \& Saúde Coletiva, 16(8), 3403-3412. Retirado de https://www.researchgate.net/profile/Lia_G_da_S/publication/5 1589643 Factors associated with the lifestyle of military police officers/links/54cfa7bc0cf24601c0951ebb.pdf Acesso em 12 março 2017. 
de Oliveira, D.F. (2015). Juventudes sitiadas: Cotidianos de violência e a interface com as políticas de segurança pública e de prevenção à violência (Mestrado acadêmico, Universidade

Estadual do Ceará). Retirado de
http://uece.br/politicasuece/dmdocuments/Deinair_Ferreira_de _liveira.pdf acesso em 26 de março de 2017.

de Oliveira, K. L., \& dos Santos, L. M. (2010). Percepção da saúde mental em policiais militares da força tática e de rua. Sociologias, 12(25), p. 227. de Souza Minayo, M. C., de Assis, S. G., \& de Oliveira, R. V. C. (2011). Impacto das atividades profissionais na saúde física e mental dos policiais civis e militares do Rio de Janeiro (RJ, Brasil). Ciência \& Saúde Coletiva,16(4), 21992209.

Enrique, R. (1992). El Hombre Light: Una vida sin valores. La sexualidad vacía y sin rumbo, Paseo de las castellanas. Madrid: Grupo Planeta, 61-63. Gardner, H. (1995). Inteligências múltiplas: a teoria na prática. Howard Gardner; tradução de Maria Adriana Veríssimo Veronese. Porto Alegre: Artes médicas.

Guirado, M., \& Albuquerque, J. A. G. (1987). Psicologia institucional. São Paulo: epu.

Maia, H., Dias, A. P. B. H., Costa, C. R. C. M., Delou, C. M. C., Oliveira, F. M. A., \& Thompson, R. (2011). Neurociências e desenvolvimento cognitivo. Rio de Janeiro: Wak Editora, 1.

Paiva, C. H. A., \& Teixeira, L. A. (2014). Reforma sanitária e a criação do Sistema Único de Saúde: notas sobre contextos e autores. Hist Cienc Saude Manguinhos, 15-35.

Richardson, R. J. (1999). Pesquisa Social: métodos e técnicas/Roberto Jarry Richardson: colaboradores José Augusto de Souza Peres (et al). São Paulo, Atlas.

Souza, E. R. D., \& Minayo, M. C. D. S. (1995). 0 impacto da violência social na saúde pública do Brasil: década de 80. In Saúde em debate (Vol. 79, pp. 87-116). Hucitec. 
Tadeu, T. (2009). Nós, ciborgues: o corpo elétrico e a dissolução do humano. Antropologia do ciborgue: as vertigens do pós-humano. Belo Horizonte: autêntica. 2, 7-15.

Universidade Estadual do Ceará (2011) http://www.uece.br/covio/dmdocuments/regional_VI.pdf acesso em 05 de abril 2017. 